\title{
Proactive Approach in Detecting Elderly Subjects with Cognitive Decline in General Practitioners' Practices
}

\author{
M. Hanzevacki ${ }^{a}$ G. Ozegovic ${ }^{b} \quad$ I. Simovic $^{a} \quad$ Z. Bajic ${ }^{c}$ \\ ${ }^{a}$ Health Care Center Zagreb Zapad, ${ }^{b}$ Center for Elderly People Drenovacka, and ${ }^{\mathrm{C} B i o m e t r i c a}$ \\ Health Care, Zagreb, Croatia
}

\section{Key Words}

Cognitive decline, early detection $\cdot$ Cognitive impairment, no dementia $\cdot$ General practitioners $\cdot$ Mild cognitive impairment $\cdot$ Mini-Mental State Examination $\cdot$ Montreal Cognitive Assessment

\begin{abstract}
Background: Although cognitive decline is a common finding among the elderly and is considered a risk factor for developing dementia, it is rarely diagnosed by general practitioners (GPs). Aim: To evaluate cognitive function with the Mini-Mental State Examination (MMSE) and the Montreal Cognitive Assessment (MoCA) in asymptomatic subjects in daily GP practice and compare subjects who confirmed having cognitive problems with subjects who did not. Methods: 388 consecutive subjects $>65$ years of age who consulted their GP were interviewed and tested with MMSE and MoCA. Results: None of the study subjects spontaneously complained of cognitive or memory problems. 155 subjects (39.94\%) confirmed having cognitive problems and $233(60.05 \%)$ did not even when asked. The prevalence of mild cognitive impairment (MCl) was $18.30 \%$ (95\% Cl 14.36-22.04) and the prevalence of cognitive impairment/no dementia (CIND) was $17.27 \%$ (95\% Cl 13.50-21.04). Delayed memory recall as a separate cognitive domain in MoCA was significantly worse in subjects with $\mathrm{MCl}(p=0.00958)$ and in those with CIND $(p=$ 0.0208). Conclusion: There is a significant number of patients in daily GP practices with unrecognized, but objectively verifiable, cognitive deficits who do not report having cognitive problems. They can be identified by assessment with MMSE and MoCA already in the GP practice.
\end{abstract}




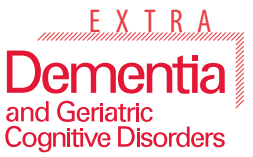

\begin{tabular}{l|l}
\hline Dement Geriatr Cogn Disord Extra 2011;1:93-102 \\
\hline DOI: 10.1159/000327076 & $\begin{array}{l}\text { @ 2011 S. Karger AG, Basel } \\
\text { www.karger.com/dee }\end{array}$ \\
\hline Published online: April 8, 2011 &
\end{tabular}

Hanzevacki et al.: Detecting Cognitive Decline in the Elderly

\section{Introduction}

Severity of cognitive deficit varies significantly in the elderly, and numerous attempts have been made to classify the boundaries between normal and pathological aging [1]. The following two concepts have most frequently been used in the literature: (1) The concept of mild cognitive impairment (MCI) describes a heterogeneous condition with cognitive characteristics between normal aging and dementia [1-3]. MCI is currently defined as a syndrome with memory impairment or other cognitive deficits that does not interfere substantially with personal affairs nor result in inability to live independently [4]. (2) 'Cognitive impairment/no dementia' (CIND) is a classification term that has been used in populationbased epidemiological studies to capture a broad range of these milder forms of impairment in cognition $[4,5]$. By definition, CIND permits the inclusion of all individuals whose cognitive performance is below average but who do not meet dementia criteria within a diagnostic category $[4,5]$. CIND does not require any specific domain(s) of cognitive impairment $[4,5]$. It can also be applied to patients seeking assessment of their cognitive difficulties in clinical settings. However, the breadth of this categorization implies a significant heterogeneity of its clinical, behavioral, and neuropsychological features $[6,7]$.

Patients or caregivers usually wait and only report a cognitive complaint to a professional when the symptoms are already obvious and advanced. In that light, one would expect especially patients satisfying the criteria for MCI or CIND rarely to complain of their deficits. In general, cognitive impairment frequently remains unrecognized even by medical personnel [5]. There are estimations that only 25\% of patients with MCI or Alzheimer's disease are recognized in the general practice [6]. It has been established that screening with formalized screening tests is superior to general clinical judgment [7].

General practitioners (GPs) are the professionals with the most detailed insight into their patients' daily activities; they are able to evaluate patients' complaints and may inquire about certain complaints if appropriate. Their central position in health care enables them to collect additional information regarding cognitive decline compared to a previous cognitive level and to detect loss of competence. They should be the first person informed on any psychological illness and are thus able to initiate and implement cognitive evaluation from a comprehensive biopsychosocial point of view [8].

To our knowledge, this is the first study which evaluates cognitive impairment and its prevalence with two brief global cognitive tests - the Mini-Mental State Examination (MMSE) and the Montreal Cognitive Assessment (MoCA) - in the daily routine of a GP [9-14]. The aim of the study was to evaluate cognitive function with the MMSE and the MoCA in asymptomatic subjects in the daily GP practice and compare subjects who confirmed having cognitive problems with subjects who did not.

\section{Subjects and Methods}

This cross-sectional study included a random sample of 388 consecutive subjects $>65$ years of age who consulted their GPs in their practice. It is part of a longitudinal epidemiological study in Zagreb, Croatia, aimed to evaluate the early clinical manifestations of dementia in primary care. The approval of the ethical committees has been obtained at the health care institutions where the study was implemented. The study was performed according to the institutional guidelines and the principles outlined in the Declaration of Helsinki [15]. Written informed consent was obtained from all the study subjects.

Patients with medical documentation confirming dementia or psychosis, deafness or blindness, or those who refused to participate were excluded. The study was performed by 4 


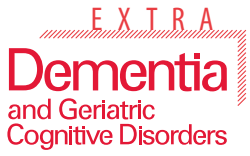

\begin{tabular}{l|l}
\hline Dement Geriatr Cogn Disord Extra 2011;1:93-102 \\
\hline \begin{tabular}{l|l} 
DOI: 10.1159/000327076 & $\begin{array}{l}\text { C 2011 S. Karger AG, Basel } \\
\text { www.karger.com/dee }\end{array}$ \\
Published online: April 8, 2011 &
\end{tabular} \\
\hline
\end{tabular}

Hanzevacki et al.: Detecting Cognitive Decline in the Elderly

Table 1. Demographic characteristics of subjects included into the study stratified according to cognitive impairment on MoCA, on MMSE, on MoCA and MMSE, and no impairment

\begin{tabular}{lccccc}
\hline & MoCA & MMSE & $\begin{array}{l}\text { MoCA/ } \\
\text { MMSE }\end{array}$ & $\begin{array}{l}\text { No } \\
\text { impairment }\end{array}$ & $\begin{array}{l}\text { Total study } \\
\text { sample }\end{array}$ \\
\hline $\begin{array}{l}\text { Subjects, } \mathrm{n} \\
\text { Sex }\end{array} \quad 316^{*}$ & $153^{*}$ & 150 & 67 & 388 \\
$\quad$ Male & 120 & 58 & 57 & 29 & 151 \\
$\quad$ Female & 196 & 95 & 93 & 38 & 237 \\
Age & 125 & 71 & 68 & 27 & 153 \\
$\quad$ 65-74 years & 132 & 49 & 46 & 23 & 168 \\
$\quad$ 75-84 years & 59 & 33 & 36 & 17 & 67 \\
$\quad \begin{array}{l}\text { S5 years } \\
\quad \text { Confirming cognitive problems }\end{array}$ & 121 & 59 & 58 & 31 & 155 \\
$\quad$ Not confirming cognitive problems & 195 & 94 & 92 & 36 & 233 \\
\hline
\end{tabular}

* The number of patients identified as cognitively impaired on MoCA and MMSE was significantly different. McNemar $\chi^{2}=29.49309 ;$ d.f. $=1 ; \mathrm{p}<0.0001$.

trained GPs in 4 independent GP practices from June 1 to October 31, 2010. Included GP practices covered the total population of 7,850 people in the Zagreb area.

Nurses in each of the practices informed the patients briefly about the study upon arrival at the GP practice. The physician completed the regular visit and immediately after that asked for informed consent and completed the MMSE and MoCA standard questionnaires $[16,17]$. The time needed to complete each questionnaire was recorded. Then, patients were asked two questions: (1) Did you observe any problems with your memory or any other cognitive function lately? (2) How do you perceive your general health status during the last 4 weeks? For the second question, one of the following options could be chosen: much worse, worse, no change, better, and much better. Age, sex, years of education and presence or absence of depression or other psychiatric disorders were recorded.

Patients who confirmed having problems with memory or other cognitive functions and who had an MMSE score $>24$ and an MoCA score $<26$ were diagnosed as having MCI [18, 19]. CIND was diagnosed based on the results of the MMSE [20]. Patients with results $<1$ SD below the mean adjusted for age and education were classified as having CIND. Those with MMSE scores $\leq 19$ were excluded since they were very likely to have dementia.

We used the MMSE despite a known lack of sensitivity, which is in some studies as low as $18 \%$, but it was the appropriate instrument for our study due to its specificity of $100 \%$ in detecting general cognitive decline, its efficacy in a GP practice setting, and the fact that it is still the most widely used cognitive screening instrument $[9,21]$.

Based on published results obtained with the MoCA test $[10,22]$ designed to measure visuospatial/executive function, naming, memory, attention, language, abstraction, delayed recall, and orientation with $90 \%$ sensitivity and $87 \%$ specificity, we used it as an additional test in order to assure sensitivity in detecting subjects with very mild cognitive deficit [10]. MoCA cutoff scores in Croatia proved to be equivalent to western European countries [17]. Basic demographic characteristics of study subjects are presented in table 1.

\section{Statistics}

For assessment of qualitative variables we used the $\chi^{2}$ test with Yates corrections for the $2 \times 2$ contingency tables. Correlation for quantitative data was assessed with Pearson's cor- 


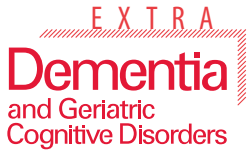

\begin{tabular}{|c|c|}
\hline \multicolumn{2}{|c|}{ Dement Geriatr Cogn Disord Extra 2011;1:93-102 } \\
\hline $\begin{array}{l}\text { DOI: 10.1159/000327076 } \\
\text { Published online: April 8, } 2011\end{array}$ & $\begin{array}{l}\text { (c) } 2011 \text { S. Karger AG, Basel } \\
\text { www.karger.com/dee }\end{array}$ \\
\hline
\end{tabular}

Hanzevacki et al.: Detecting Cognitive Decline in the Elderly

Table 2. Comparison of patients who confirmed having cognitive deficits when asked and patients who did not

\begin{tabular}{lcc}
\hline & Confirming & Not confirming \\
\hline Sex & $51^{*}$ & 100 \\
$\quad$ Male & $104^{*}$ & 133 \\
Female & & \\
Cognitive status** & 121 & 195 \\
$\quad$ Impaired on MoCA & $22.65 \pm 2.68$ & $22.47 \pm 2.31$ \\
$\quad$ MoCA score & 59 & 94 \\
Impaired on MMSE & $24.40 \pm 2.39$ & $24.53 \pm 2.39$ \\
$\quad$ MMSE score & 58 & 92 \\
Impaired on MoCA and MMSE & 31 & 36 \\
$\quad$ No impairment & 155 & 233 \\
Total & &
\end{tabular}

Values are numbers or mean $\pm \mathrm{SD} .{ }^{*}$ Among patients confirming cognitive deficits, there were significantly more women (Pearson's $\chi^{2}=3.927497$; d.f. $=1 ; \mathrm{p}=$ 0.04751). ${ }^{*}$ Scores on MoCA and MMSE were not significantly different between subjects confirming and subjects not confirming cognitive or memory problems.

relation. Differences between average quantitative variables were analyzed with Student's t test. MMSE and MoCA results were compared with the McNemar test. The calculations were performed by the commercially available software Statistica 6.0.

\section{Results}

There were 237 women (61.08\%) and 151 men (38.92\%) included in the study. None of them spontaneously mentioned any memory or other cognitive problems. Among them, 155 subjects (39.94\%) confirmed having cognitive problems and 233 (60.05\%) did not when asked by a physician (table 2 ). Women confirmed cognitive problems statistically more often than men. Among those who confirmed cognitive problems, $104(66.23 \%)$ were women and 51 (33.77\%) men ( $\mathrm{p}=0.04751)$.

Mean MMSE score \pm SD was $25 \pm 2.39$ and mean MoCA score \pm SD was $23 \pm 2.46$. On MMSE, $34.20 \%$ of subjects who confirmed having a cognitive problem and $34.14 \%$ of those who did not scored above the median. On MoCA, $41.94 \%$ of subjects who confirmed having a cognitive problem and $33.90 \%$ of those who did not scored above the median. There was no significant difference in MMSE and MoCA scores between those confirming a deficit and those who did not confirm a memory or cognitive problem [MMSE score (mean \pm $\mathrm{SD}$ ): confirming $24.40 \pm 2.39$ vs. not confirming $24.53 \pm 2.39$; MoCA score (mean $\pm \mathrm{SD}$ ): confirming $22.65 \pm 2.68$ vs. not confirming $22.47 \pm 2.31$; table 2]. Subjects who confirmed cognitive problems more frequently rated their general health as declining during the past 4 weeks, and those who did not confirm cognitive problems rated their general health as recently unchanged. The difference was significant $(\mathrm{p}<0.0001)$.

Cognitive impairment according to the MMSE and MoCA questionnaires was recognized in 150 subjects [93 (62.00\%) female, $57(38.00 \%)$ male]. 153 subjects [95 (62.09\%) female, 58 (37.91\%) male] were cognitively impaired according to MMSE, and 316 patients [196 (62.03\%) female, 120 (37.97\%) male] were cognitively impaired according to MoCA. The difference between the results on MMSE and MoCA was statistically significant (McNemar 
Table 3. Key characteristics of the subjects classified as having MCI or CIND, and total sample

\begin{tabular}{llll}
\hline & MCI & CIND & Total sample \\
\hline MMSE score, mean \pm SD & $25.94 \pm 1.03$ & $21.02 \pm 1.48$ & $24.48 \pm 2.39$ \\
MoCA score, mean \pm SD & $23.08 \pm 1.47$ & $20.07 \pm 2.58$ & $22.54 \pm 2.46$ \\
Subjects, n & 71 & 67 & 388 \\
Age, years & $75.21 \pm 7.00$ & $76.11 \pm 7.64$ & $75.12 \pm 7.19$ \\
Sex, female/male & $47 / 24$ & $38 / 29$ & $237 / 151$ \\
Self-perception: subjects confirming cognitive & & & 40.20 \\
$\quad$ problems, \% & 100 & 44.07 & \\
\hline
\end{tabular}

$\chi^{2}=29.49309 ;$ d.f. $=1 ; \mathrm{p}<0.0001$; table 1$)$. There were 163 subjects $(42.01 \%)$ who were diagnosed as cognitively impaired by MoCA, but not by MMSE. Only 3 patients were classified as cognitively impaired by MMSE and not by MoCA. 319 patients $(82.22 \%)$ proved to be cognitively impaired on both MMSE and MoCA, and 69 patients (17.78\%) were diagnosed as being cognitively without deficit on both tests.

The prevalence of MCI was $18.30 \%$ (95\% CI 14.36-22.04) or 71 subjects. Among them, $47(66.18 \%)$ were women and $24(33.82 \%)$ men. The difference between sexes was significant $(\mathrm{p}=0.019$; table 3$)$. The prevalence of CIND was $17.27 \%$ (95\% CI 13.50-21.04) or 67 subjects. Among them, 38 (56.72\%) were women and 29 (43.28\%) men (the difference was not significant; table 3). Delayed memory recall analyzed as a separate cognitive domain on MoCA was significantly worse in subjects with MCI $(\mathrm{p}=0.00958)$ and in those with CIND ( $\mathrm{p}=0.0208$; fig. 1). All subjects who were diagnosed as having MCI did not have CIND, and all subjects diagnosed as having CIND did not have MCI. Among CIND subjects, 28 (48.18\%) confirmed having a cognitive or memory problem. Female CIND subjects admitted cognitive problems significantly more often than male CIND subjects [21/40 (52.50\%) women vs. 5/28 (17.86\%) men; $\mathrm{p}=0.00382]$.

Subjects who confirmed cognitive deficits scored significantly better on orientation to time. The highest score (5) was achieved by $107 / 155$ subjects $(69.03 \%)$ who confirmed versus $132 / 233$ subjects $(56.65 \%)$ who did not confirm cognitive deficits. The lowest recorded score (3) was reached by $3 / 155$ subjects (1.94\%) who confirmed versus $27 / 233$ subjects (11.59\%) who did not confirm cognitive deficits $(\mathrm{p}=0.00103)$. In orientation to space, all subjects scored either 4 or 5 among 5 possible scores. Significantly more subjects confirming cognitive problems scored 5 [117/155 (75.48\%) vs. 139/233 (59.66\%); $\mathrm{p}=0.00127]$. In the clock-drawing test, possible scores were $0,1,2$, or 3 . Those confirming cognitive problems scored 3 significantly more often $[96 / 155(61.94 \%)$ vs. 90/233 (38.63\%)]. Those not confirming cognitive problems scored either 1 or 2 significantly more often [143/233 (61.37\%) vs. 59/155 (38.06\%); p = 0.00002]. In serial discounting, possible scores were $0,1,2$, or 3 . Those confirming cognitive problems scored 3 significantly more often [110/155 (70.97\%) vs. 135/233 (57.94\%)]. Those who did not confirm cognitive problems scored 1 or 2 significantly more often [98/233 (42.06\%) vs. 45/155 (29.03\%); $\mathrm{p}=0.03357]$.

In contrast, those who did not confirm cognitive problems scored significantly better on delayed memory recall and on writing a sentence. In delayed memory recall, possible scores were $0,1,2,3,4$, or 5 . Those who did not confirm having cognitive problems more frequently scored 3, 4, or 5 [199/233 (85.41\%) vs. 75/155 (48.39\%)]. Those who did confirm cognitive problems had significantly more often scores 1 or 2 [80/155 (51.61\%) vs. 34/233 (14.50\%); p < $0.000001]$. For writing a sentence, possible scores were 0 or 1 . Those who did not confirm cognitive problems scored significantly more often 1 [177/233 (75.97\%) vs. 102/155 (65.81\%)]. 


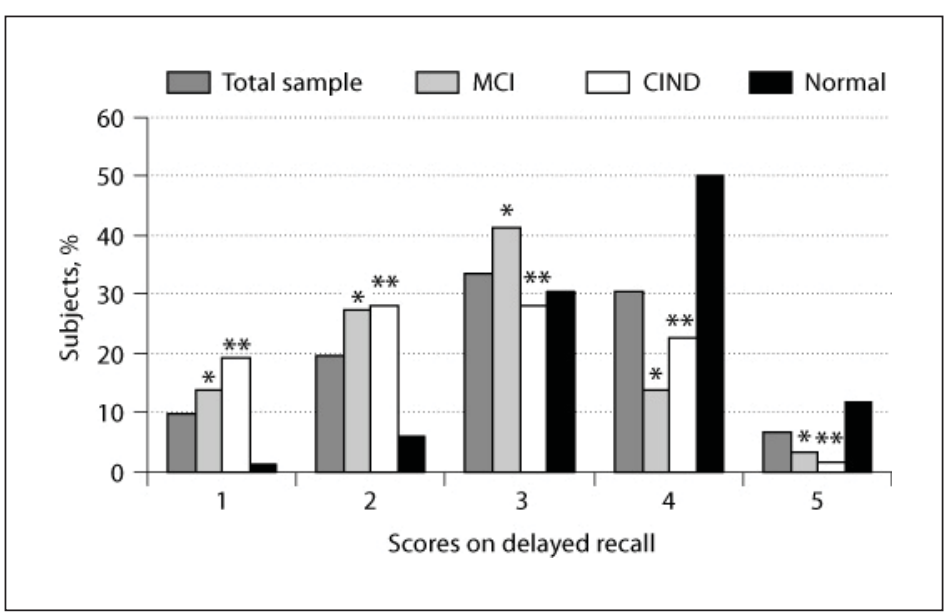

Fig. 1. Scores on delayed memory recall in subjects with different cognitive status [total sample, MCI, CIND, and subjects with no detectable cognitive deficit (normal)]. * Subjects with MCI had significantly worse results than all other groups (Pearson's $\chi^{2}$ test $=11.43724$; d.f. $=3 ; \mathrm{p}=0.00958$. ${ }^{*}$ CIND subjects had significantly worse results than subjects without CIND (Pearson's $\chi^{2}$ test $=11.57726$; d.f. $=4 ; \mathrm{p}=$ 0.02079). Delayed recall was evaluated as part of the MoCA test.

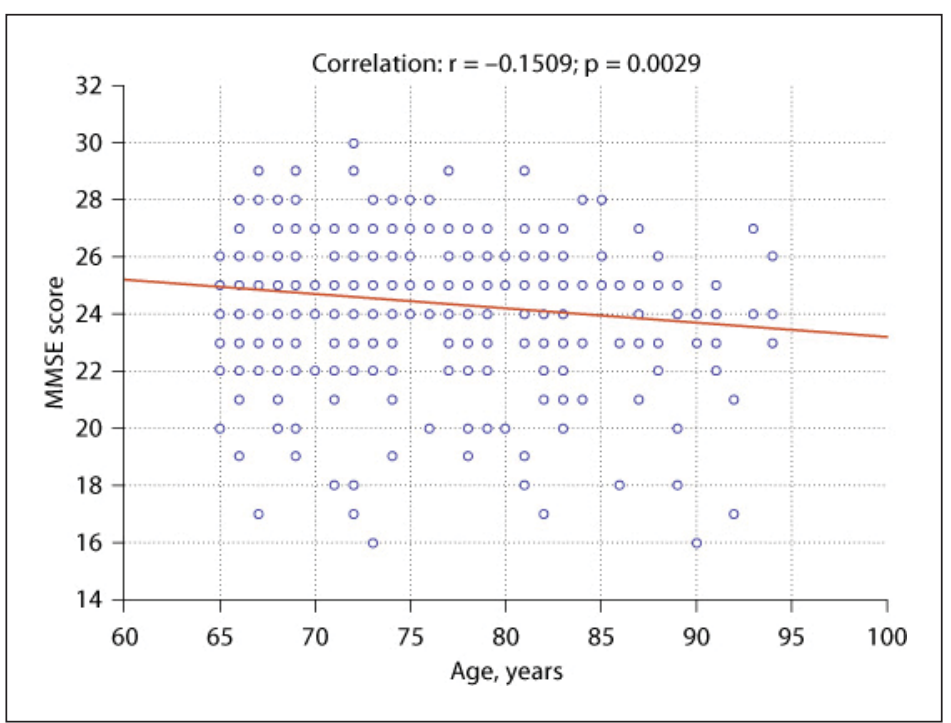

Fig. 2. Correlation between the results scored on MMSE and age.

Those who confirmed cognitive problems scored significantly more often 0 [53/155 (34.19\%) vs. $56 / 233$ (24.03\%); $\mathrm{p}=0.02920$ ].

Older subjects scored worse on MMSE with $r=-0.1509$ and $p=0.003$ (fig. 2). We did not observe any significant correlation with duration of education. Average time needed for MMSE completion as a separate part of the visit was $7 \mathrm{~min} 23 \mathrm{~s}(7.44 \pm 2.59 \mathrm{~min})$ and for MoCA 10 min $6 \mathrm{~s}(10.10 \pm 2.50 \mathrm{~min})$. 


\section{Discussion}

The individual's subjective evaluation of his/her own memory and cognitive function may not reflect actual functional capabilities and, consequently, performance on objective testing $[23,24]$. Inaccurate self-perception may indicate a lack of awareness of changes in cognitive function or may be connected with difficulties with memory [24-27].

In our results, there was no difference in average scores on brief global cognitive tests between those subjects who confirmed and those who did not confirm cognitive deficits, which is in accordance with findings by Luck et al. [14]. We separately analyzed cognitive functions within the MMSE and MoCA and found only delayed memory recall significantly worse in MCI and CIND subjects. This is in accordance with other authors [27, 28]. Worse memory function could play a role in patients' perception of actual cognitive status.

One can speculate that when a person's delayed memory recall is impaired, he/she will probably assume that cognitive function as a whole is impaired, still assuming that the awareness of memory deficit is preserved. Similar to delayed memory recall, subjects who confirmed having a cognitive problem reported a significantly lower score for their general health status during the preceding 4 weeks. It is difficult to decide whether this general observation concerning health influences the self-perception of a person's cognition or whether, on the other hand, persons with really impaired cognitive function judge their general health as impaired.

It is possible that memory complaints or perceived decline in cognitive function in old age are not solely determined by actual cognitive ability but also by other variables, such as personality traits, personal and psychological well-being, and subjective health [29-31]. The influence of cognitive functions, such as memory-related cognitive domains, attention, working memory, and information processing speed, probably exists but has not been explained [32]. There is ample evidence that slower information processing due to aging can cause slower rehearsal and impoverishment of information, resulting in a poorer memory performance $[33,34]$. In that light, we also observe a discrepancy in our results since less than half of the subjects characterized as having CIND confirmed a cognitive deficit. The mean MMSE score of these subjects was almost 5 points lower than the score of those diagnosed as having MCI (who confirmed having a cognitive problem even as a diagnostic criteria), suggesting that worse cognitive function might be an explanation for worse self-perception of cognitive function.

In order to achieve an early detection of cognitive problems, it would be important to benefit from the fact that persons with an increased risk or even early signs of dementia are frequently present at the GP practice with some other medical problem not explicitly related to memory or cognition. A GP thoroughly examining a patient from a biopsychosocial point of view will most probably evaluate the patient's complaint or absence of complaint in the right way and initiate further workup if necessary [9].

Among all subjects confirming a cognitive problem we found significantly more women. This was evident also in the subgroups characterized as having MCI or CIND. This finding correlates with the PAQUID study in 1994 [35]. It is also in agreement with data by Apostolova and Cummings [36] on the most frequent neuropsychiatric symptoms associated with $\mathrm{MCI}$, i.e. depression, apathy, and anxiety, which is known to be more frequent among women [36-38]. However, Luck et al. [14] discovered the opposite in GP patients: significantly more male subjects complained about cognitive problems. In the same study, a significantly higher prevalence of MCI was observed among female patients when subjective complaint was not part of the diagnostic criteria for MCI. This was not the case when self-complaint was part of the criteria [14]. In line with our results, Mol et al. [38] found significantly more women among GP patients reporting forgetfulness. Depression has been more frequent but 
not statistically significantly among female subjects in our study. Verified depressive symptoms were equally present in subjects who confirmed having cognitive problems and in subjects who did not. We intend to evaluate the possible influence of concomitant neuropsychological disorders on cognitive or memory complaints in the future.

We found the prevalence of MCI to be $18.30 \%$, which is in accordance with prior studies [11]. Cooper et al. [12] found a rate of $17 \%$ for 'milder non-disabling degrees of cognitive impairment' in GP patients aged $\geq 65$ years diagnosed by a short rating scale [12]. More recently, population-based studies have revealed prevalence rates of MCI diagnosed according to Petersen's criteria $[39,40]$. The special prevalence of MCI among GP patients approached in their homes has been thoroughly researched by Artero et al. [13] and reported to be $16.6 \%$. Luck et al. [14] interviewed GP patients in a similar setting and found a prevalence of $14.8 \%$ among patients $75-79$ years of age. The CIND prevalence of $17.27 \%$ in our study is very similar to the MCI prevalence; however, the affected subjects were completely different. This strongly points to a heterogeneity of patients with cognitive deficits.

One limitation of our study is that we used solely the brief global cognitive screening tests MMSE and MoCA in order to characterize cognitively impaired subjects. As expected, MoCA proved to be significantly more sensitive $[10,22]$. However, it is appropriate to consider both tests for the early detection and initial evaluation of cognitive function in the GP practice, although a majority of subjects were recognized as cognitively impaired by MoCA, since we do not know the false-positive rate at this point and since MMSE was invented and proven valid for the early evaluation of dementia. The primary objective in the GP practice would be to identify high-risk individuals and to transfer them to further evaluation in a specialized clinical setting.

In Croatia, there is a very limited number of specialized centers treating patients with cognitive problems, and they mostly focus on more advanced stages of cognitive deficits and different types of dementia [41]. Consequently, primary care physicians have an important role in detecting patients' problems and especially in their evaluation and follow-up. A GP's insight into daily activities and family dynamics evaluated by a biopsychosocial approach could additionally improve the quality of clinical judgment in the daily practice with elderly patients with different levels of cognitive deficits.

In the light of time constraints, the time of almost 18 min needed to implement the MMSE and MoCA tests incorporated into a regular GP visit represents a significant burden for the GP during daily practice. This puts delayed memory testing in the focus of our interest since delayed memory proved to be significantly correlated with general cognitive decline [42]. As it has also been described to be correlated with the risk of progression to dementia, it could be considered as one of the first tests to be implemented for recognizing potential patients with a cognitive deficit at the primary care level where the priority is to recognize the deficit. A delayed memory recall test could increase awareness of possible cognitive problems among patients and could cause them to pay more attention to cognitive functions in daily activities [43].

\section{Conclusion}

There is a significant proportion of unrecognized subjects in the daily GP practice with an objectively verifiable cognitive deficit who do not report it even when asked. They can be diagnosed with MMSE and MoCA testing already in the GP practice. Further research is needed to understand factors such as sex or psychiatric conditions which have an influence on whether or not subjects complain about cognitive problems and to recommend the optimal procedure for early detection of subjects with cognitive impairment. 


\section{References}

-1 Portet F, Ouset PJ, Viser PJ, Frisoni GB, Nobili F, Scheltens P, Vellas B, Touchon J: Mild cognitive impairment (MCI) in medical practice: a critical review of the concept and new diagnostic procedure. Report of the MCI Working Group of the European Consortium on Alzheimer's disease. J Neurol Neurosurg Psychiatry 2006;77:714-718.

2 Petersen RC: Conceptual overview; in Petersen RC (ed): Mild Cognitive Impairment: Aging to Alzheimer's Disease. New York, Oxford University Press, 2003, pp 1-14.

-3 Small BJ, Fratiglioni L, Viitanen M, Winblad B, Backman L: The course of cognitive impairment in preclinical Alzheimer disease: three- and 6-year follow-up of a population-based sample. Arch Neurol 2000;57:839-844.

-4 Graham JE, Rockwood K, Beattie BL, Eastwood R, Gauthier S, Tuokko H, McDowell I: Prevalence and severity of cognitive impairment with and without dementia in an elderly population. Lancet 1997;349:1793-1796.

-5 Ebly EM, Hogan DB, Parhad IM: Cognitive impairment in the nondemented elderly. Results from the Canadian Study of Health and Aging. Arch Neurol 1995;52:612-619.

-6 Feldman H, Levy AR, Hsiung GY, Peters KR, Donald A, Black SE, Bouchard RW, Gauthier SG, Guzman DA, Hogan DB, Kertesz A, Rockwood K: A Canadian cohort study of cognitive impairment and related dementias (ACCORD): study methods and baseline results. Neuroepidemiology 2003;22: 265-274.

-7 Peters KR, Graf P, and Hayden S, Feldman H: Neuropsychological characterization of cognitivelyimpaired-not-demented (CIND) individuals: clinical comparison data. Clin Neuropsychol 2004;18: 208-228.

8 Boustani M, Sachs G, Callahan M: Can primary care meet the biopsychosocial needs of older adults with dementia? J Gen Intern Med 2007;22:1625-1627.

-9 Pezzotti P, Scalmana S, Mastromattei A, DiLallo D: The accuracy of the MMSE in detecting cognitive impairment when administered by general practitioners: a prospective observational study. BMC Fam Pract 2008;9:29.

-10 Nasreddine ZS, Phillips NA, Bedirian V, Charbonneau S, Whitehead V, Collin I, Cummings JL, Chertkow H: The Montreal Cognitive Assessment, MoCA: a brief screening tool of mild cognitive impairment. J Am Geriatr Soc 2005;53:695-699.

$\checkmark 11$ Bush C, Kozak H, Elmslie T: Screening for cognitive impairment in the elderly. Can Fam Physician 1997;43:1763-1768.

-12 Cooper B, Bickel H, Schäufele M: Dementia diseases and minor cognitive impairments in elderly patients in general practice. Results of a cross-sectional study (in German). Nervenarzt 1992;63:551560.

-13 Artero S, Petersen R, Touchon J, Ritchie K: Revised criteria for mild cognitive impairment: validation within a longitudinal population study. Dement Geriatr Cogn Disord 2006;22:465-470.

-14 Luck T, Riedel-Heller S, Kaduszkiewicz H, Bickel H, Jessen F, Pentzek M, Wiese B, Koelsch H, van den Bussche H, Abholz H, Moesch H, Gorfer S, Angermeyer M, Maier W, Weyerer S: Mild cognitive impairment in general practice: age-specific prevalence and correlate results from the German study on ageing, cognition and dementia in primary care patients (AgeCoDe). Dement Geriatr Cogn Disord 2007;24:307-316.

15 World Medical Association Declaration of Helsinki. Ethical Principles for Medical Research Involving Human Subjects (http://www.wma.net/en/30publications/10policies/b3/17c.pdf).

-16 Folstein MF, Folstein SE, McHugh PR: 'Mini-mental state'. A practical method for grading the cognitive state of patients for the clinician. J Psychiatr Res 1975;12:189-198.

17 The Montreal Cognitive Assessment. The $\mathrm{MoCA}^{\odot}$ is a cognitive screening test designed to assist health professionals for detection of mild cognitive impairment (http://www.mocatest.org).

-18 Winblad B, Palmer K, Kivipelto M, Jelic V, Fratiglioni L, Wahlund LO, Nordberg A, Bäckman L, Albert M, Almkvist O, Arai H, Basun H, Blennow K, de Leon M, DeCarli C, Erkinjuntti T, Giacobini E, Graff C, Hardy J, Jack C, Jorm A, Ritchie K, van Duijn C, Visser P, Petersen RC: Mild cognitive impairment: beyond controversies, towards a consensus - report of the International Working Group on Mild Cognitive Impairment. J Intern Med 2004;256:240-246.

19 Li YS, Meyer JS, Thornby J: Longitudinal follow-up of depressive symptoms among normal versus cognitively impaired elderly. Int J Geriatr Psychiatry 2001;16:718-727. 
20 Frisoni GB, Fratiglioni L, Fastbom J, Viitanen M, Winblad B: Mortality in nondemented subjects with cognitive impairment: the influence of health-related factors. Am J Epidemiol 1999;150:10311044.

-21 Ismail Z, Rajji TK, Shulman KI: Brief cognitive screening instruments: an update. Int J Geriatr Psychiatry 2010;25:111-120.

-22 Smith T, Gildeh N, Holmes C: The Montreal Cognitive Assessment: validity and utility in a memory clinic setting. Can J Psychiatry 2007;52:329-332.

23 Jonker C, Geerlings MI, Schmand B: Are memory complaints predictive for dementia? A review of clinical and population-based studies. Int J Geriatr Psychiatry 2000;15:983-991.

-24 Vogel A, Stokholm J, Gade A, Andersen BB, Hejl AM, Waldemar G: Awareness of deficits in mild cognitive impairment and Alzheimer's disease: do MCI patients have impaired insight? Dement Geriatr Cogn Disord 2004;17:181-187.

25 Clement F, Belleville S, Gauthier S: Cognitive complaint in mild cognitive impairment and Alzheimer's disease. J Int Neuropsychol Soc 2008;14:222-232.

-26 Podewils LJ, McLay RN, Rebok GW, Lyketsos CG: Relationship of self-perceptions of memory and worry to objective measures of memory and cognition in the general population. Psychosomatics 2003;44:461-470.

-27 Roberts JL, Clare L, Woods RT: Subjective memory complaints and awareness of memory functioning in mild cognitive impairment: a systematic review. Dement Geriatr Cogn Disord 2009;28:95-109.

28 Clare L, Markova I, Verhey F, Kenny G: Awareness in dementia: a review of assessment methods and measure. Aging Ment Health 2005;9:394-413.

29 Commissaris CJ, Ponds RW, Jolles J: Subjective forgetfulness in a normal Dutch population: possibilities for health education and other interventions. Patient Educ Couns 1998;34:25-32.

30 Niederehe G: The significance of memory complaints in later life: methodological and theoretical considerations; in Lomranz J (ed): Handbook of Aging and Mental Health: An Integrative Approach. New York, Plenum Press, 1998, pp 417-434.

- 31 Pearman A, Storandt M: Predictors of subjective memory in older adults. J Gerontol B Psychol Sci Soc Sci 2004;59:P4-P6.

32 Kausler DH: Learning and Memory in Normal Aging. San Diego, Academic Press, 1994.

-33 Busse A, Bischkopf J, Riedel-Heller SG, Angermeyer MC: Subclassifications for mild cognitive impairment: prevalence and predictive validity. Psychol Med 2003;33:1029-1038.

-34 Lopez OL, Jagust WJ, DeKosky ST, Becker JT, Fitzpatrick A, Dulberg C, Breitner J, Lyketsos C, Jones B, Kawas C, Carlson M, Kuller LH: Prevalence and classification of mild cognitive impairment in the Cardiovascular Health Study Cognition Study: part 1. Arch Neurol 2003;60:1385-1389.

-35 Gagnon M, Dartigues JF, Mazaux JM, Dequae L, Letenneur L, Giroire JM, Barberger-Gateau P: Selfreported memory complaints and memory performance in elderly French community residents: results of the PAQUID Research Program. Neuroepidemiology 1994;13:145-154.

-36 Apostolova LG, Cummings JL: Neuropsychiatric manifestations in mild cognitive impairment: a systematic review of the literature. Dement Geriatr Cogn Disord 2008;25:115-126.

-37 Robert PH, Berr C, Volteau M, Bertogliati C, Benoit M, Sarazin M, Legrain S, Dubois B: Apathy in patients with mild cognitive impairment and the risk of developing dementia or Alzheimer's disease: a one-year follow-up study. Clin Neurol Neurosurg 2006;108:733-736.

- 38 Mol ME, van Boxtel MP, Willems D, Jolles J: Do subjective memory complaints predict cognitive dysfunction over time? A six-year follow-up of the Maastricht Aging Study. Int J Geriatr Psychiatry 2006;21:432-441.

39 Petersen RC (ed): Mild Cognitive Impairment: Aging to Alzheimer's Disease. New York, Oxford University Press, 2004.

-40 Petersen RC: Mild cognitive impairment as a diagnostic entity. J Intern Med 2004;256:183-194.

-41 Martinic Popovic I, Seric V, Demarin V: Mild cognitive impairment in symptomatic and asymptomatic cerebrovascular disease. J Neurol Sci 2007;257:185-193.

-42 Pinto E, Peters R: Literature review of the Clock Drawing Test as a tool for cognitive screening. Dement Geriatr Cogn Disord 2009;27:201-213.

-43 Jorm AF, Christensen H, Korten AE, Henderson AS, Jacomb PA, Mackinnon A: Do cognitive complaints either predict future cognitive decline or reflect past cognitive decline? A longitudinal study of an elderly community sample. Psychol Med 1997;27:91-98. 